\title{
Analysis of Benefits and Problems of Leadership Training
}

\author{
Taufani C. Kurniatun* \\ Educational Administration Program \\ Universitas Pendidikan Indonesia \\ Bandung, Indonesia \\ *taufani@upi.edu
}

\author{
Moeh Adam, Haris Marzuki Susila, M. Djamaludin \\ Center of Management Competency Development \\ Ministry of Public Works and Housing \\ Jakarta, Indonesia
}

\begin{abstract}
This study aims to analyze the problems of leadership training. The method in this study used qualitative method with data processing using Nvivo 12 which is given to 9 alumni of leadership training, 3 instructor, and 3 direct supervisors. The results showed that there were benefits and problems encountered related to the implementation of leadership training. First, the benefits of leadership training is to support the duties of the organizational units and supported the implementation of the change project. Second, the problem relates to the implementation in the workplace/organizations leadership training alumni at the Ministry of Public Works and Housing. The problems include applying the change project, there are problems that can hinder, namely there are other big projects, constrained by routine work, transfers and promotions, mentor support that is not optimal and changes in organizational structure.
\end{abstract}

\section{Keywords—problem analytic, benefits of leadership training}

\section{INTRODUCTION}

Leadership training is a means to form and develop leadership, including leadership of government organizations. It cannot be denied that leadership has an important role in the organization which is a kind of person's strength to influence or change the values, behavior and attitudes of others to achieve organizational goals [1-3].

The characteristics of an effective leader here are someone who provides direction, is committed to working in groups to achieve organizational goals and objectives [4]. The most important leadership is trying to communicate and motivate members to work or tasks carried out by members, besides that leadership strategies must always be innovative, not stay put and follow old traditional rules [5,6].

In previous studies related to leadership, leadership development remains one of the least explored matters

Avolio and Quisenberry [7], Harrison [8], Martinelli and Erzikova [9], Subramoni et al. [10]. In fact, leadership development is important because considering the changing organizational development, leaders must be more innovative.
So far there have been many leadership training in various forms, several studies reveal about leadership training and the majority relates to funds in an organization's training budget that tend to be allocated for leadership [11,12], namely leadership to improve leadership strategies and organizational performance [13]

Research on leadership training that examines the problems of leadership training in relation to implementing training that has been implemented in organizational units is still rarely done. Therefore, this study aims to reveal how leadership training problems are based on the perceptions of leadership training participants or alumni.

\section{A. Related Work}

Leadership Training Design and Implementation can be seen based on four criteria, namely Reaction, Learning, Transfer and Results which is familiar with the Kirkpatrick method [14].

1) Reaction: The reaction describes the components of the attitude of effectiveness and consists of the attitudes of the trainee towards the training (for example, the use and satisfaction of the training). The reaction of the trainees can serve as an indicator of motivation

2) Learning: Learning outcomes can be categorized as affective, cognitive and psychomotor. This leadership development or leadership training program is designed to produce changes in the ability of trainees to engage in roles and processes by presenting new information [15].

3) Transfer: The main purpose of leadership training is to create positive behavior change in leaders in the workplace.

4) Results: Results is an evaluative method that reflects the effect of a training program on achieving organizational goals. Results are often defined here as the benefits of training compared to program costs [14]. So that in this result, it can be seen that the impact that occurs is in the form of a better change after the implementation of leadership training. 


\section{B. Our Contribution}

This article describes the analysis of problems in leadership training, so that it can be seen the obstacles that cause leadership training to be applied to organizations or workplaces. So that it becomes a recommendation for training improvements that will be carried out or can become a practical study on related training.

\section{Paper Structure}

The rest of the organized as follows, Section 2 introduction the preliminaries used in this paper, which include a literature review that used in the framework. Section 3 presents methods; data based on framework, concludes the paper and presesnt direction for future research. Section 4 Ackowledgement.

\section{METHOD}

The method in this study used qualitative method with data processing using Nvivo 12. This study was conducted at the Center of Management Competency Development, Ministry of Public Works and Housing. Respondents in this study were 9 alumni of leadership training, 3 instructor, and 3 direct supervisors. Data collection techniques in this study were interviews and focus group discussion. The thing that is being asked is the problem and the method used to solve the problem.

\section{RESULTS AND DISCUSSION}

All the data obtained are reduced, summarized, the main things are selected, and are focused on the important things in the form of nodes with NVivo 12. The data results are selected based on certain categories in order to provide a sharper picture of the results of the observations. Furthermore, the data display process is carried out by selecting pieces of data that have the same thing to be categorized according to the subject matter or research focus. Then it is made in the form of a diagram or matrix making it easier to see patterns of relationships with other data.

Based on the results of research that have been processed through the Nvivo 12 application, the following results are obtained:

\section{A. Obstacles}

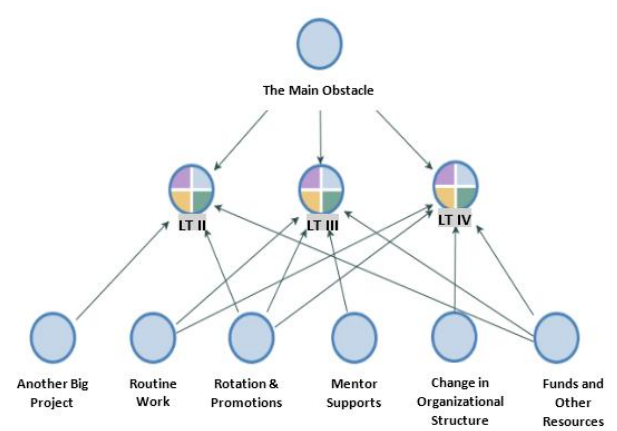

Fig. 1. Obstacles of leadership training.
Based on the data obtained in figure 1, the analysis stages were then carried out using the Nvivo 12 Plus. Data visualization as in Figure 1 above. From this figure, it can be seen that there are 6 nodes which are categorized as the main obstacle. The main obstacle is the obstacles in the implementation of the training results in the work unit. The six nodes are obtained from the results of the summary, reduction and analysis of the main things and are focused on the things that are important. In the figure, it can be seen that Leadership Training as LT II, LT III and LT IV are respondents from the study.

The obstacles faced by the training alumni include; first, rotation and promotion so that there are several obstacles such as still requiring adaptation time to be able to complete work in accordance with the main tasks and functions. Second, funds and other resources, this is due to the Covid-19 pandemic, which has led to relaxation of the State Budget. Routine work is also one of the main obstacles, this is due to the busy workload, one of which is because of concurrently two positions. Next, there are some obstacles that the training alumni have, namely changes in organizational structure, lack of mentor support and other big projects.

As we know, the leadership training that is carried out is expected to have an impact as a form of change after attending the training. The problems that occur are the obstacles faced by alumni who are training participants in implementing change projects in leadership training, that there are various obstacles that have been mentioned above. Meanwhile, according to Kirkpatrick, results are an evaluative method that reflects the effect of a training program in achieving organizational goals, the results here are often defined as the benefits of training compared to program costs.

\section{B. How to Overcome the Obstacles}

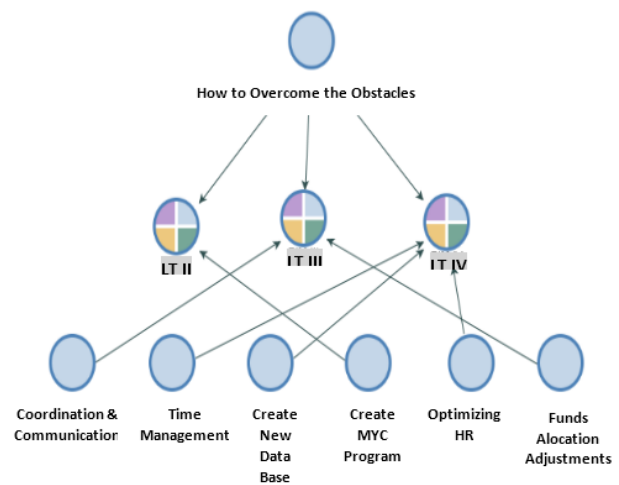

Fig. 2. How to ovecome the obstacles of leadership training.

Based on the results of the analysis using the Nvivo 12 Plus in figure 2, the methods used by the training alumni to overcome the obstacles they experience are firstly through coordination and communication even though they are done online, but coordination and communication are still maintained, then through time management, namely using the available time to carry out the change project, then create a 
new database, create a MYC program, optimize existing human resources and adjust the allocation of funds.

The obstacles or problems faced are not necessarily left unchecked, based on other research, the training that is carried out definitely requires a lot of funds, the majority of funds in the training budget in organizations tend to be allocated to leadership [11,12]. Therefore, the obstacles faced must be resolved so that the training that has been carried out does not give the impression of "less useful". Ways to overcome obstacles are carried out to improve organizational performance, this is in line with the research of Bro et al. [13], that leadership training is carried out to improve leadership strategies and organizational performance.

\section{Supporting Factors}

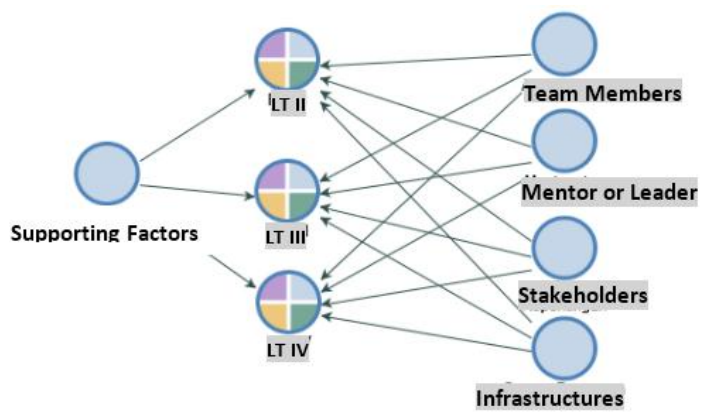

Fig. 3. Supporting factors of leadership training.

Based on the results of the analysis using the Nvivo 12 Plus, data visualization is obtained regarding the supporting factors in the implementation of the training results as in Figure 3 above. The main factor that supports the implementation of the change project according to alumni is the team members, namely colleagues who are very supportive of the implementation of the change project, a mentor or leader who supports the implementation of the change project, In addition, stakeholders also support the implementation of the change project, then the last one is the supporting infrastructure so that the reform program can be implemented.

This supporting factor greatly influences the impact of the training that has been attended by leadership training alumni, because the organization is a system so that cooperation is needed, as well as in the work of training alumni in carrying out their job duties for the progress of the organization.

\section{Forms of Support Provided by the Leader}

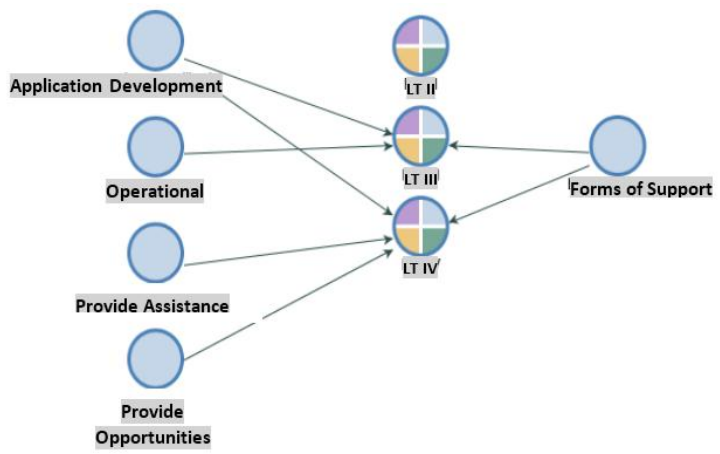

Fig. 4. Forms of support provided by the ledear.

Another thing that is focused on in this analysis is the form of support provided to training alumni. The form of support provided by leader in realizing this change project was assistance in making Sippera and SIKAD applications (See figure 4). Then there is also operational assistance such as commitment, availability of resources, and facilitation of infrastructure in realizing the change project. Next, the support provided by the leader is in the form of assistance, the last form of support provided by leader in the form of opportunities to implement change projects.

\section{E. Beneficiaries}

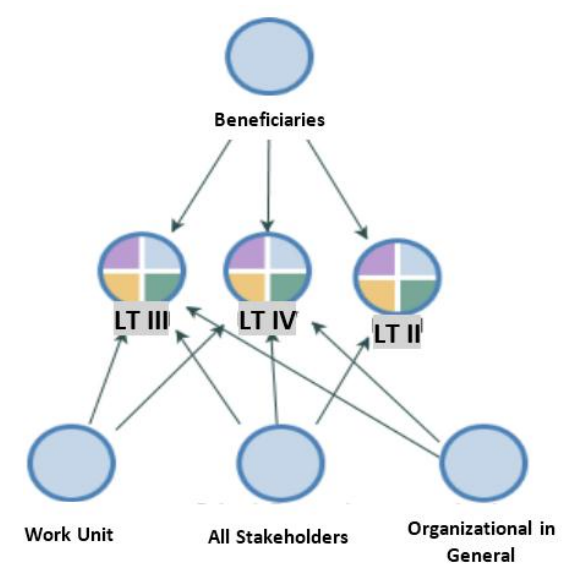

Fig. 5. Beneficiaries

Based on the results of the analysis using the Nvivo 12, the most beneficiary of this change project is the work unit, all stakeholders in general (See in figure 5); Ministry of Public Works and Housing, then all internal stakeholders (promoters and defenders), the organizational unit of the Directorate General of Highways and the ranks of the industrial external (latent and apathetic) Road Implementation Agency, and road user community associations. Other beneficiaries are the organization in general. 


\section{F. Benefits of Training}

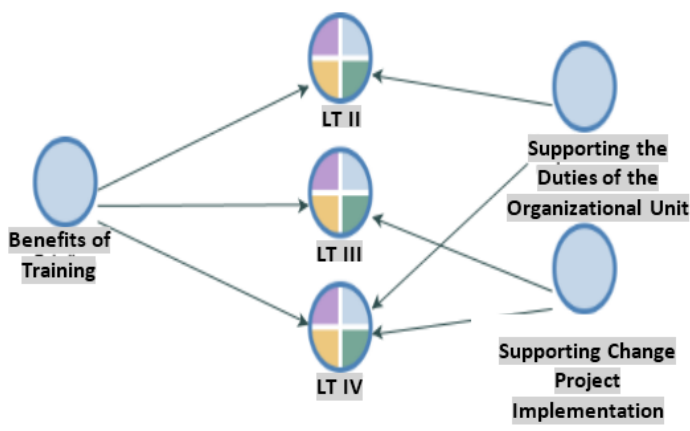

Fig. 6. Benefits of training.

Based on the results of the analysis using the Nvivo 12 Plus show in figure 6 , the benefits of training felt by alumni are the results of training to support the duties of the organizational units, the material provided is also very supportive of the implementation of activities. Another benefit that was felt that this training supported the implementation of the change project.

\section{G. Training Assessment}

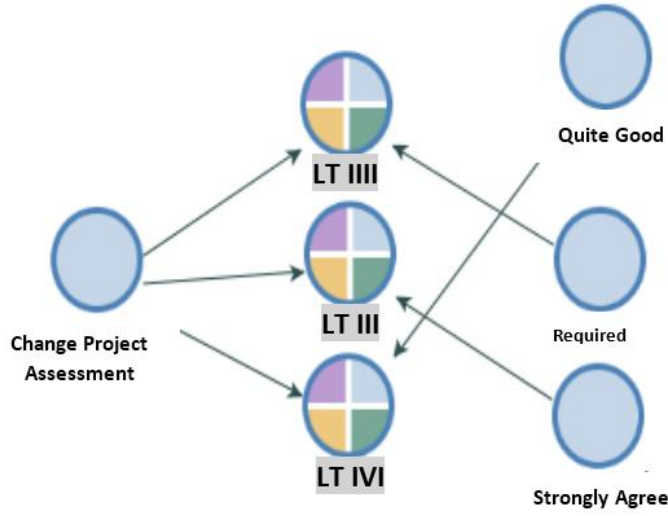

Fig. 7. Training assessment.

Based on the results of the analysis using the Nvivo 12 Plus, there are several assessments given by the training alumni in figure 7; first, the participants strongly agreed that this training should be continued; second, this training is also required to plan, implement and evaluate activities in accordance with the duties and functions in each work unit; third, this training was considered good enough by the participants.

That refers to the research results above, the problems in training are generally related to the obstacles of implementing training in the workplace or leadership strategies and organizational performance, This is in line with the research of Rinfret and Lagace [16] that the training that has been followed is an effort that aims to improve the quality of organizational performance and the competence of managers or leaders assigned to overcome these challenges.
Likewise, to overcome obstacles, it can be done in various ways, namely by coordinating and communicating, proper time management, optimizing the human resources involved and adjusting the allocation of funds. When referring to solutions in overcoming these obstacles, the leader must have the right strategy, This is in line with the research of Unsworth and Mason [17] that a strategy that is owned and implemented by the leader is to use a more constructive thinking pattern in dealing with management challenges, and finally found to increase competence by always learning.

\section{CONCLUSION}

Leadership training is felt to be carried out as well as possible. Because based on the results above, there are benefits of leadership training, namely leadership training is to support the duties of the organizational units and supported the implementation of the change project. Besides the urgency of the leader as a driving force of the organization, means leaders who are able to provide innovation or change and can carry out their duties properly can improve organizational performance. However, in its implementation there are obstacles or problems after leadership training alumni have implemented a change project in the workplace, among them are constrained by other great projects, hampered by routine work so that the change project has not been implemented optimally, rotation and promotions that cause the change project not to be carried out completely, mentor support that has not been optimal and changes in organizational structure.

\section{ACKNOWLEDGMENT}

We would like to thank The Center of Management Competency Development, Ministry of Public Works and Housing for supporting this work.

\section{REFERENCES}

[1] V.C. Ganta and J.K. Manukonda, "Leadership During Change And Uncertainty In Organizations," International Journal of Organizational Behaviour \& Management Perspectives, vol. 3, no. 3, pp. 1183, 2014

[2] Jackson and Parry, "A Very Short, Interesting and Reasonably Cheap Book About Studying Leadership," London: SAGE Publication, vol. 208, no. 2, pp. 25, 2008.

[3] P.G. Northhouse, Leadership: Theory and Practice, (3rd. ed). London: Sage Publications Ltd, 2004.

[4] A. Wasim and A. Imran, "The Role of Leadership in Organizational Change," Relating the successful organizational change to visionary and innovative leadership, vol. 3, no. 2, pp. 9, 2010.

[5] F. Graetz, M. Rimmer, A. Smith, and A. Lawrence, Leadership for Change. Managing organizational change (3rd edition), 6, 144, 2010.

[6] D. Coghlan and P. Coughlan, "Effecting Change and Learning in Networks Through Network Action Learning," The Journal of Applied Behavioral Science, vol. 51, no. 3, pp. 375-400, 2015.

[7] B.J. Avolio, J.B. Avey and D. Quisenberry, "Estimating return on leadership development investment," The Leadership Quaterly, vol. 21, pp. 633-644, 2010.

[8] R.T. Harrison, "Leadership, leadership development and all that jazz," Leadership, vol. 13, no. 1, pp. 81-99, 2017. 
[9] D. Martinelli and E. Erzikova, "Public relations leadership development cycle: A cross-cultural perspective,” Public Relations Review, vol. 43, pp. 1062-1072, 2017.

[10] M. Subramony, J. Segers, C. Chadwick and A. Shyamsunder, "Leadership development practice bundles and organizational performance:The mediating role of human capital and social capital," Journal of Business Research, vol. 83, pp. 120-129, 2018.

[11] M. Ho, Investment in learning increases for fourth straight year, 2016. Retrieved

https://www.td.org/Publications/Magazines/TD/TDArchive/ 2016/11/Investment-in-Learning-Increases-for-Fourth Straight- Year

[12] K. O'Leonard, The corporate learning factbook: Benchmarks, trends and analysis of the U.S. training market. Oakland, CA: Bersin \& Associates, 2014.

[13] L.L. Bro, L.B. Andersen, A. Bøllingtoft, T. Eriksen, A.L. Holten, C.B Jacobsen and N. Westergaard-Nielsen, Leadership training, leadership strategies and organizational performance. IRSPM conference in Ottawa 9-12 April, 2014.

[14] D. Kirkpatrick, "Techniques for evaluating training programs," Journal of the American Society for Training and Development, vol. 13, pp. 3-9, 1959.

[15] D.V. Day, "Leadership development: A review in context," The Leadership Quarterly, vol. 11, pp. 581-613, 2000.

[16] N. Rinfret and M.C. Lagace, "Le cercle des jeunes leaders : Relever le defi d'accompagner la releve des hauts gestionnaires du secteur public quebecois," Rapport de recherche realise pour le Secretariat du Conseil du Tresor, ENAP, Quebec, pp. 1-74, 2016.

[17] K.L. Unsworth and C.M. Mason, "Help yourself: The mechanisms through which a self-leadership intervention influences strain," Journal of Occupational Health Psychology, vol. 17, pp. 235-245, 2012. 